\title{
Stability and elastic properties of $\beta$ Ti-alloys for biomedical application designed with electronic parameters
}

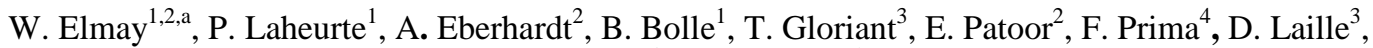 \\ P. Castany ${ }^{3}$ and M. Wary ${ }^{2}$. \\ ${ }^{1}$ Laboratoire d'Etude des Textures et Application aux Matériaux (LETAM), Metz, France. \\ ${ }^{2}$ Laboratoire de Physique et Mécanique des Matériaux (LPMM), Metz, France. \\ ${ }^{3}$ Laboratoire de Science Chimique/Chimie métallurgie (SCR/CM), Rennes, France. \\ ${ }^{4}$ Laboratoire de Physico-Chimie des Surfaces, Groupe de Métallurgie Structurale, Paris, France.
}

\begin{abstract}
Titanium alloys are receiving a big attention for biomedical applications. Recently, $\beta$ type titanium alloys composed of non-toxic elements are being developed for these applications. The aim of this paper is to study mechanical properties and deformation mechanisms of three beta titanium alloys designed with similar values of Bo-Md and e/a ratio. The contribution of electronic approach to predict beta phase stability is also discussed. The microstructural analysis and the mechanical characterization are carried out for different metallurgical states (cold working, solution treatment and aging treatment). Effects of aging treatment at low temperature is also investigated, showing that isothermal holding at $400^{\circ} \mathrm{C}$ for $0,6 \mathrm{ks}$ after cold working improves the mechanical properties of alloys.
\end{abstract}

\section{Introduction}

Metallic biomaterials such as stainless steels, Co-Cr alloys and titanium alloys as Ti-Al-6V were mainly utilized for implants. But, it was reported that some alloying element (V, Co) can present a potential toxic effect [1]. Recently, new beta type titanium alloys composed of non-toxic elements such as $\mathrm{Nb}, \mathrm{Ta}, \mathrm{Zr}$... are developed for biomedical application because of their excellent properties such as superelasticity, shape memory effect, low Young's modulus, corrosion resistance and their good biocompatibility. The superelasticity and the low Young's modulus in titanium alloys are attributed to the reversible martensitic transformation between the $\beta$ parent phase and the $\alpha$ " martensite phase. The temperature of this transformation can be controlled by addition of elements.

Several studies were performed on these titanium alloys. Miyazaki and al. show that the Ti-(2225) at.\% $\mathrm{Nb}$ and $\mathrm{Ti}-(25.5-27)$ at.\% $\mathrm{Nb}$ alloys exhibit respectively the shape memory effect and superelastic behavior, while Ti-(28-29) at.\% $\mathrm{Nb}$ alloy does not present either shape memory effect or superelasticity [2]. The effect of $\mathrm{Zr}$ addition on the mechanical properties, the shape memory effect and the phase stability was studied by J.I. Kim and al. [3]. The yielding stress inducing plastic deformation increases with increasing the amount of $\mathrm{Zr}$ in the alloy and that is because of the solid solution hardening.

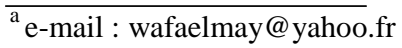

This is an Open Access article distributed under the terms of the Creative Commons Attribution-Noncommercial License 3.0, which permits unrestricted use, distribution, and reproduction in any noncommercial medium, provided the original work is properly cited. 
Quaternary alloys were widely studied for medical applications because of their interesting properties: Ti-(20, 25, 30, 35)Nb-10Ta-5Zr (\% mass) [4], Ti-30Nb-(0, 5, 10, 15, 20) Ta-5Zr [5], Ti$35 \mathrm{Nb}-2 \mathrm{Ta}-3 \mathrm{Zr}$ [6], Ti-(13-35.5)Nb-(5-22)Ta-(4-7.2)Zr [7]. In particular, Ti-29Nb-13Ta-4.6Zr alloy (TNTZ) developed by Niinomi [8] which presents a better compromise between the various characteristics required for biomedical alloys: a low Young's modulus, good mechanical properties and excellent properties in fatigue.

In this work, three alloys: binary $\mathrm{TN}$ : $\mathrm{Ti}-37 \mathrm{Nb}$, ternary $\mathrm{TNZ}$ : $\mathrm{Ti}-36 \mathrm{Nb}-7 \mathrm{Zr}$ and quaternary TNZT: Ti-28Nb-5Zr-11Ta (\% mass) are investigated. Their superelastic behavior and their elastic properties are investigated through cyclic loading unloading tensile test. The phases existing in alloys after the various thermo-mechanical treatments are identified from the optical micrographs, XRD profiles and TEM observations.

\section{Experimental}

\subsection{Strategy of composition's choice}

The choice of titanium alloys composition is established on two observations. On one hand, the number of valence electrons e/a, which is a dominant factor in controlling the elastic properties of bcc transition metals. The shear modulus is as low as the e/a value tends towards 4.2-4.3 [9].

On the other hand, on the Morinaga's approach assuming a correlation between the $\beta$ phase stability and the elastic properties of the bcc titanium alloys [10]. This approach, based on a molecular orbital method, allows determining theoretically two electronic parameters. Bo is the bond order which measure the covalent bond strength between $\mathrm{Ti}$ and an alloying elements and $\mathrm{Md}$ is the d-orbital energy level of alloying transition-metal.

For the three alloys, the average values of Bo and Md are calculated by taking the compositional average of each parameter using the following mathematical formulae:

$$
\begin{aligned}
& \overline{B o}_{\text {alloy }}=\Sigma\left(\mathrm{Bo}_{\mathrm{i}} * \mathrm{X}_{\mathrm{i}}\right) / 100 \\
& \overline{M d}_{\text {alloy }}=\Sigma\left(\mathrm{Md}_{\mathrm{i}} * \mathrm{X}_{\mathrm{i}}\right) / 100
\end{aligned}
$$

With $\mathrm{X}_{\mathrm{i}}$ is the atomic composition of element $\mathrm{i}, \mathrm{Bo}_{\mathrm{i}}$ and $\mathrm{Md}_{\mathrm{i}}$ are the respective values of $\mathrm{Bo}$ and $\mathrm{Md}$ for each alloying element. These compositions are chosen in such a way to obtain values of Bo-Md and e/a as close as possible (Table 1) in order to verify the contribution of this electronic parameters to predict the beta phase stability.

\subsection{Experimental procedures}

These three alloys are elaborated with magnetic levitation melting method under atmosphere of argon. The ingots are homogenized at $1173 \mathrm{~K}$ for $21.6 \mathrm{ks}$ and another treatment at $1173 \mathrm{k}$ for $1.8 \mathrm{ks}$ followed by water quenching. The composition determined after elaboration of these alloys, Bo, Md and e/a values are given by Table. 1. The ingots are cold rolled $(\mathrm{CW})$ with reduction of thickness of $75 \%$. Some specimens are encapsulated in quartz tubes and then solution treated (ST) at $1023 \mathrm{~K}$ for 3.6ks. These specimens are quenched into water by breaking the quartz tubes. Some cold rolled specimens are aged at $300^{\circ} \mathrm{C}$ and $400^{\circ} \mathrm{C}$ (CWA). X-Ray diffractometer equipped with $\mathrm{Cu}-\mathrm{K}_{\alpha}$ radiation was used to identify the constituent phases. Mechanical properties are investigated by a cyclic loading unloading tensile test with a constant strain increment. For the microstructural observation, the specimens are mechanically polished and then etched in the Kroll solution consisting of $4 \% \mathrm{HF}, 6 \% \mathrm{HNO}_{3}$ and $90 \% \mathrm{H}_{2} \mathrm{O}$. For transmission electron microscopy (TEM) observations, thin foil samples are obtained by mechanical grinding to $200 \mu \mathrm{m}$ and twin jet 
electropolishing (6\% perchloric acid in acetic acid; $22 \mathrm{~V}$ ). Conventional TEM observations are carried out using a JEOL 2000FX Electron Microscope operating at 200kV.

Table 1. Chemical composition measured of the three alloys

\begin{tabular}{cccccccc}
\hline \multirow{2}{*}{ Alloy } & \multicolumn{9}{c}{ Composition atomique (at. \%) } & $\overline{B o}$ & $\overline{M d}$ & \multirow{2}{*}{ e/a } \\
\hline Binary & 76.71 & 23.15 & 0 & 0 & 2.86 & 2.44 & 4.23 \\
Ternary & 72.12 & 23.32 & 4.56 & 0 & 2.88 & 2.46 & 4.23 \\
Quaternary & 73.33 & 19.24 & 3.55 & 3.87 & 2.87 & 2.46 & 4.23 \\
\hline
\end{tabular}

\section{Results and discussion}

\subsection{Microstructure}

The optical micrographs of the three alloys subjected to solution treatment and water quenched are given by Figure 1, it is shown that the structure of TNZ and TNZT alloys is constituted of $\beta$ equiaxed grains. For TN alloy, fine needles of martensite $\alpha$ ' are observed in $\beta$ grains. This observation is confirmed by XRD profiles shown in Figure 2 (a).

(a)

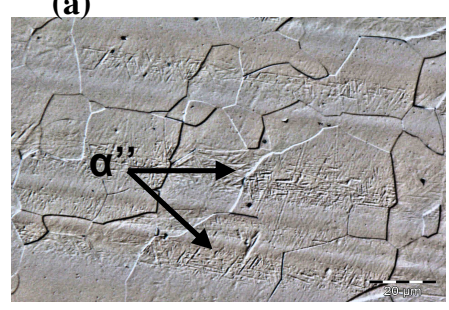

(c)

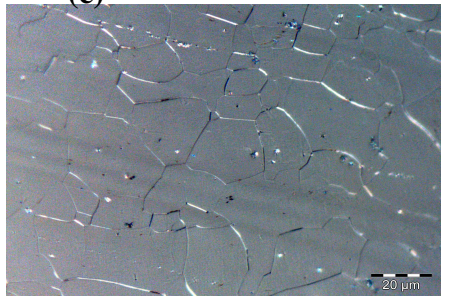

(b)

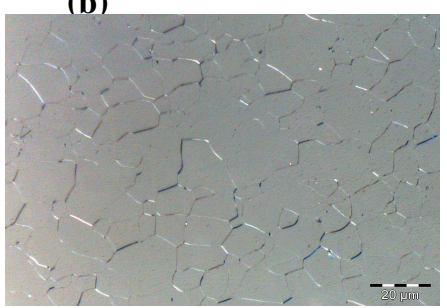

Fig. 1. Optical micrographs obtained after solution treatment: (a)TN, (b)TNZ, (c)TNZT

Figure 2 (b) shows XRD profiles of the cold rolled alloys. These alloys present a dominant $\beta$ phase. Only for TN alloy, XRD profiles show additional peaks of weak intensity corresponding to the $\alpha$ " orthorhombic martensite. The XRD profiles of the solution treated alloys which are subjected to tensile test until rupture (ST+T) are given by Figure 4 (c). Only $\beta$ peaks are observed for TNZ alloy. Both $\alpha$ " and $\beta$ peaks are observed for TN and TNZT.

(a) $\mathrm{ST}$

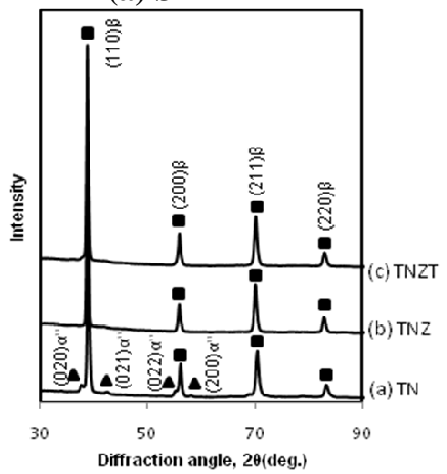

(b) $\mathrm{CW}$

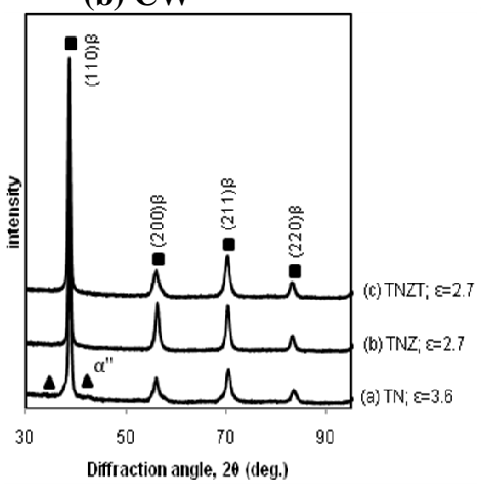

(c) $\mathbf{S T}+\mathbf{T}$

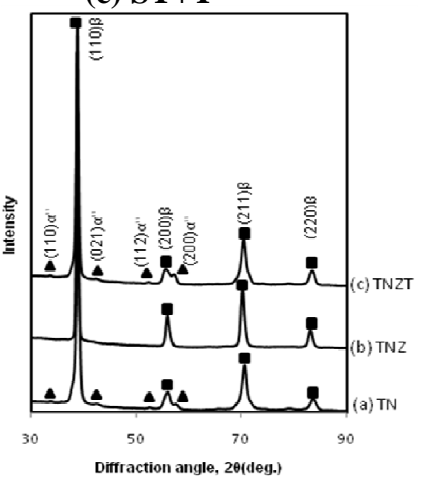

Fig. 2. X-ray diffraction profiles of the three alloys obtained after different treatment: (a)ST solution treated specimens, (b)CW cold rolled specimens and (c)ST+T solution treated followed by a tensile test until rupture. 
The presence of martensite in TN alloy could be explained by the value of Ms (martensite start temperature) which is above room temperature. Kim and al. studied the Ti-23at. \% Nb binary alloy (which is close to our TN alloy composition) and estimate its Ms temperature at 380K [11].

The TNZT solution treated alloy don't present $\alpha$ " martensite phase. The stability of $\beta$-phase of this alloy is greater comparing with TN alloy because of the presence of $\beta$ stabilizing elements (Ta and $\mathrm{Zr}$ ), and which involve a stress to induce martensite transformation. The absence of martensite $\alpha$ ' in TNZT in cold rolled and solution treated specimens is in agreement with results of Niinomi's study about Ti-29Nb-13Ta-4.6Zr alloy [12]. So for this alloy, the phase transformation from the $\beta$ phase to the $\alpha$ " phase is induced by stress during the deformation process in the $\beta$ phase (Figure 2 (c)).

The absence of the martensite for the TNZ alloy after loading lets predict that Ms temperature is even lower than Ms temperature of the TNZT alloy and the critical stress for inducing martensite is greater than the critical stress for plastic deformation.

\subsection{Tensile tests}

Mechanical characterization of these alloys is carried out with tensile tests at room temperature. Tensile loading- unloading stress-strain curves of cold rolled alloys are given by Figure 3.
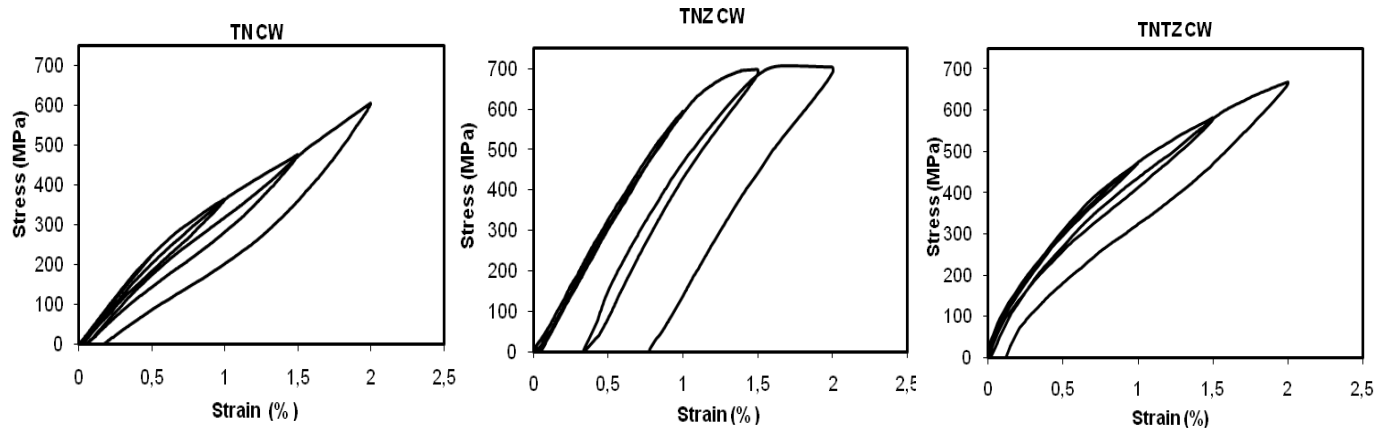

Fig. 3. Stress-strain curves of cold rolled alloys (CW).

The TNZ alloy presents a tensile strength of about $700 \mathrm{MPa}$ which is higher of $100 \mathrm{MPa}$ than the tensile strength of TN alloy. This alloy present also different curve shape from those of the TN and TNZT alloys. For TNZT alloy, the stress does not increase linearly with increasing strain, it disobeys Hooke's law. The Young's modulus values of TNZ and TNZT (defined by the slope of the tangent curve taken at the origin) are sensibly close (64 and $66 \mathrm{GPa}$, respectively) and which is greater than TN Young's modulus (47 GPa). This low value of Young's modulus could be explained by the presence of martensite after cold rolling and its variant reorientation under loading.

Figure 4 shows tensile loading- unloading stress-strain curves of solution treated alloys. The three alloys have sensibly the same values of elongation $(10 \%-12 \%)$.
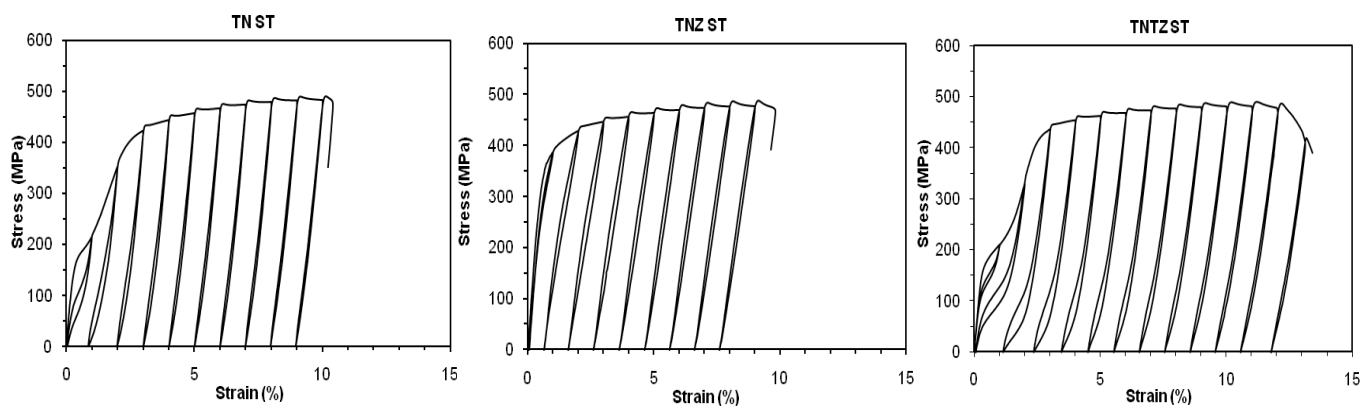

Fig. 4. Stress - strain curves of solution treated alloys at $1023 \mathrm{~K}$ for $3.6 \mathrm{ks}$. 
The values of Young's modulus are appreciably close for TN and TNZT (60 GPa) and slightly superior for TNZ (67 GPa). We presented in Figure 5 the two first cycles of tensile test of the three alloys.

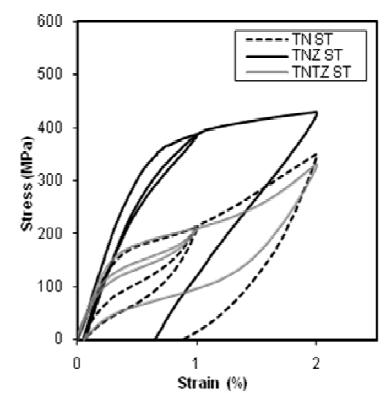

Fig. 5. Stress- strain curves of three alloys subjected to solution treatment at $1023 \mathrm{~K}$ for $3.6 \mathrm{ks}$.

The tensile curves of TN and TNZT alloys exhibit "double yielding" phenomenon (Figure 5). The first one corresponds to the critical stress for inducing the martensitic transformation upon loading and the second one the beginning of dislocation slip. Whereas, for TNZ alloy, the shape of loading-unloading curve is different, the unloading curve shows a linear reversion. No martensitic transformation is detected for this alloy. It exhibits a classical elasto-plastic behavior. The shape of these curves is justified by the microstructure of the alloys.

Perfect superelasticity was obtained at the first cycle at a strain of $1 \%$ for TN and TNZT alloys which is due to the reverse martensitic transformation from $\alpha$ "' to $\beta$ phase or due to the reorientation of martensitic variants. We noticed also that the tensile strength of TN and TNZT alloys at a strain of $1 \%$ are sensibly equal: $210 \mathrm{MPa}$, which is lower than the tensile strength of TNZ alloy with $387 \mathrm{MPa}$. That can be explained by the fact that the martensitic transformation requires a stress all the more important that the difference between the room temperature and the $\mathrm{M}_{\mathrm{s}}$ temperature is large.

For TNZ alloy, the stress does not increase much with increasing strain after yielding in the second loading. Its Ms temperature is very lower than room temperature that plastic deformation occurs before that the critical stress for inducing martensite transformation is reached.

After the second loading, the martensite induced upon loading for TNZT improves the shape recovery and it presents a superelastic behavior. Whereas, TN alloy which reveals the presence of martensite after solution treatment, does not exhibit complete superelastic strain recovery. The variants reorientation of martensite during the load-unloading cycle reduces the superelastic recovery.

\subsection{Improvement of the mechanical properties}

Different aging treatment at $300^{\circ} \mathrm{C}$ and $400^{\circ} \mathrm{C}$ are carried out for each alloy after cold rolling in order to increase the critical stress for slip deformation and then improve the superelastic behavior. Stress-strain curves of these specimens are shown in Figure 6.

The TNZT alloy is subjected to an aging treatment at the temperature of $400^{\circ} \mathrm{C}$ during $0.6 \mathrm{ks}$, $3.6 \mathrm{ks}$ and 36ks (Figure 6(c)). We noticed that the tensile strength and the Young's modulus increased with increasing the aging time $\left(\mathrm{E}_{400^{\circ} \mathrm{C}-0.6 \mathrm{ks}}=42 \mathrm{GPa}, \mathrm{E}_{400^{\circ} \mathrm{C}-3.6 \mathrm{ks}}=64 \mathrm{GPa}\right.$ and $\mathrm{E}_{400^{\circ} \mathrm{C}-}$ $36 \mathrm{ks}=80 \mathrm{GPa}$ ). However, the elongation decreased. The same observations can be established for TN and TNZ alloy by comparing tensile test at $400^{\circ} \mathrm{C}$ for $0.6 \mathrm{kand} 1.8 \mathrm{ks}$. For these three alloys, the weakest values of the Young's module are given by aged specimens at $400^{\circ} \mathrm{C}$ during $0.6 \mathrm{ks}$ with 42GPa for both TN and TNZT and 50GPa for TNZ. 
(a) TNCWA

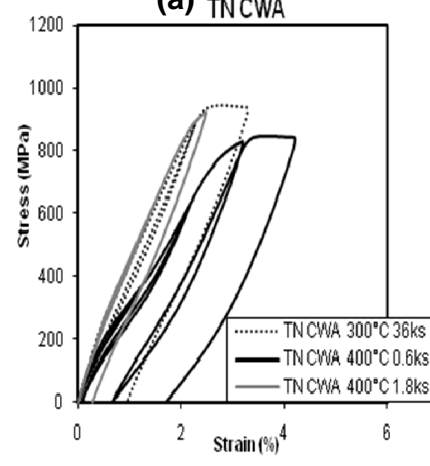

(b) TNZ CWA

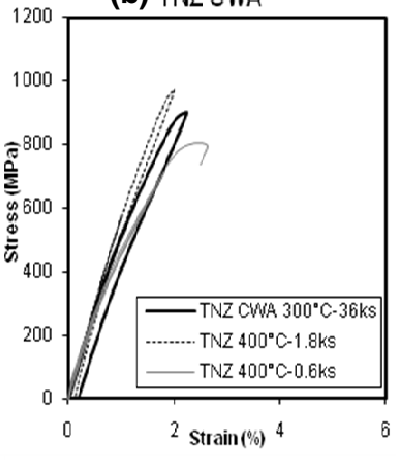

(c) TNZT CWA

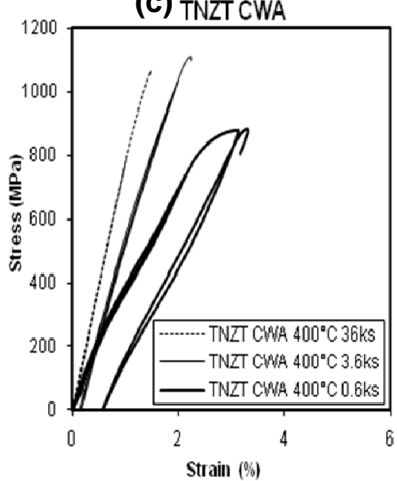

Fig. 6. Stress-strain curves of cold rolled and aged specimens: (a)TN, (b)TNZ and (c) TNZT.

From these curve, we can observe also that the most important ductility is given by the specimens having undergone the shortest isothermal holding time which is $0.6 \mathrm{ks}$ at $400^{\circ} \mathrm{C}$. On the other hand, the more important fragility is observed after a long time holding due probably to the precipitation of the omega phase. The presence of $\omega$ phase in TNZT and TN alloys aged at $400^{\circ} \mathrm{C}$ for $0.6 \mathrm{ks}$ is confirmed by the diffraction pattern given by Figure 7 .
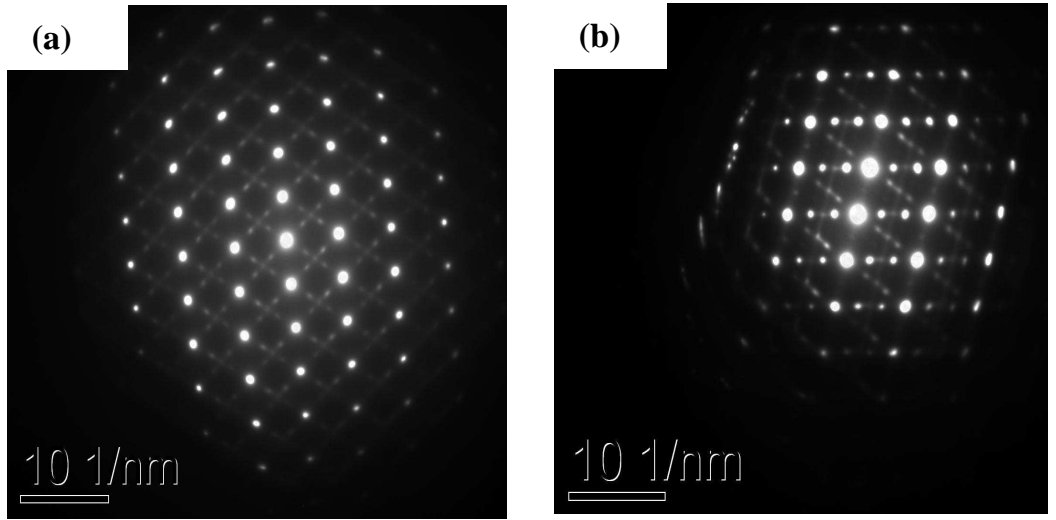

Fig. 7. Diffraction pattern of aged alloys at $400^{\circ} \mathrm{C}-0.6 \mathrm{ks}$ (CWA): (a) TNTZ along the [110] zone axis,

(b) TN along the [113] zone axis.

Histograms represented by Figure 8 summarize the evolution of the characteristics of three alloys at the various metallurgical states (ST, CW and CWA at $400^{\circ} \mathrm{C}-0.6 \mathrm{ks}$ ).

It is obvious that the tensile strength values of aged cold worked specimens (CWA) are greatly high compared with those of the solution treated specimens. And that it is owing to the combination effect of work hardening and $\omega$-phase precipitation.
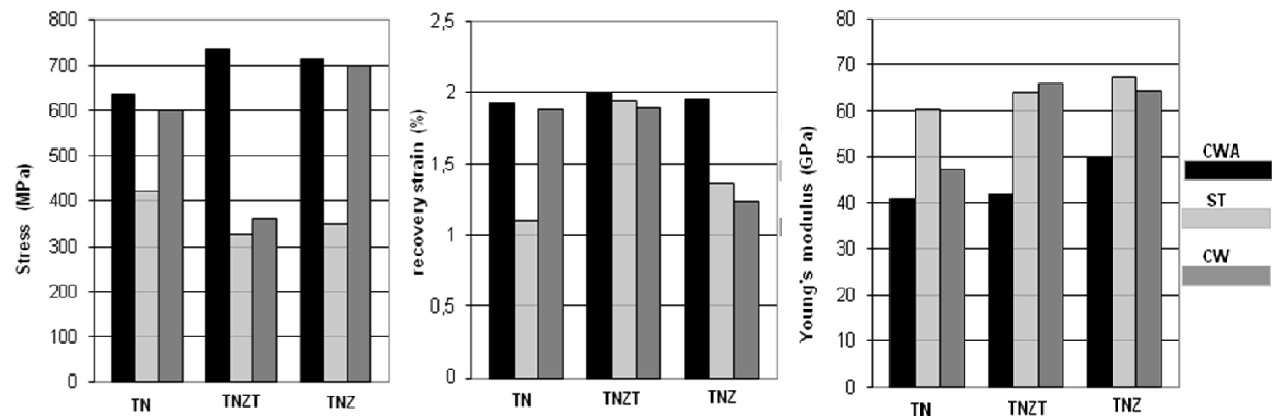

Fig. 8. Properties of the three alloys at different metallurgical states 
From these histograms, we can concluded that the aging treatment at the low temperature of $400^{\circ} \mathrm{C}$ during $0.6 \mathrm{ks}$ for cold rolled specimens improves the properties of alloys: increases recovery strain, decreases significantly Young's modulus and increases the tensile strength comparing with the properties of cold rolled and solution treated specimens. It was reported by Kim and al. that fine $\omega$ precipitates formed during aging in the temperature range 573-673 $\mathrm{K}$ are effective in increasing the critical stress for slip [11-13].

\subsection{Contribution of electronic parameters}

We present on the Bo-Md map (Figure 9) the figurative spots of the three alloys studied and the vectors showing the effect of adding elements on Bo-Md values. The $\mathrm{Nb}$ and $\mathrm{Ta}$ are both beta stabilizing elements, their alloying vectors are directed toward the beta phase field.

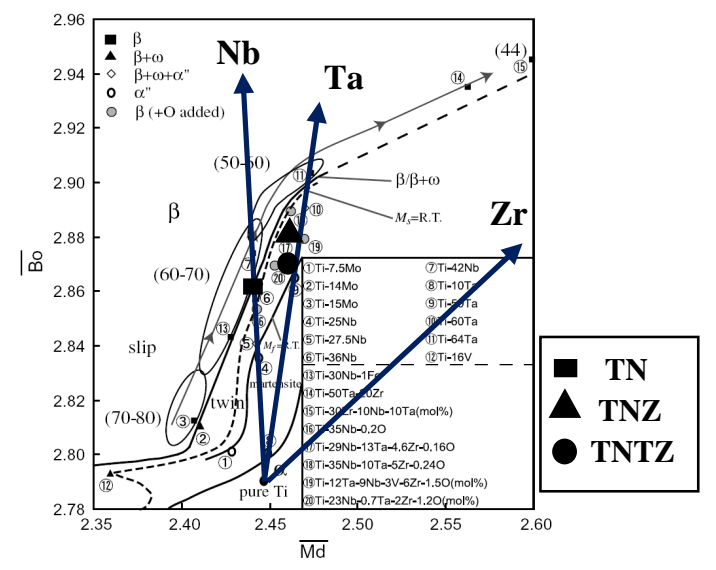

Fig. 9. Diagram Bo-Md [10]

Morinaga and al. showed a relationship between the values of the two electronic parameters and the stability phases of titanium alloys. Some discrepancies are observed between our results and the information which could be extracted from this diagram.

The position of TNZ and TNZT alloys is below the $\mathrm{M}_{\mathrm{s}}=\mathrm{RT}$ (room temperature) dotted line and above $\mathrm{M}_{\mathrm{f}}=\mathrm{RT}$, which lets predict that the quenched microstructure for this two alloys display coexistence of both $\beta$ and $\alpha$ " martensite. Whereas, the microstructural investigations in our study show no $\alpha$ " martensite phase in TNZT alloy, and for TNZ alloy the transformation from $\beta$ phase to $\alpha^{\prime \prime}$ phase is never observed.

From this diagram, the position of $\mathrm{TN}$ alloy is above the Ms=RT which lets predict that the quenched microstructure constitute of a single $\beta$ phase. Whereas, the XDR profiles and the optical micrographs reveal the presence of martensite (Figure1(a) and Figure2(a)).

The position of TNZ alloy in this diagram is closer to the Ms=RT than TNZT alloy, consequently the $\beta$-phase of TNZ is less stable than TNZT $\beta$-phase, which is contradictory with the results of the present study. This alloy presents however a typical elasto-plastic behavior. Probably because its Ms temperature is significantly lower than room temperature which is on contradiction with its close position to Ms=RT in the diagram. The stress for inducing martensitic transformation for TNZ alloy is then superior to the yield stress.

It is known that the $\beta$ phase stability in Ti-alloys changes with alloy composition and it increased with the increasing content of the $\beta$ stabilizing element. As a result, the single $\beta$-phase boundary is shifted by the addition of $\beta$ stabilizing element and consequently the boundary of Ms=RT. Therefore, the discrepancies found could be explained by the fact that the effect of adding elements on shifting boundary of the ternary and the quaternary alloys are not taken into account in this diagram. 


\section{Conclusion}

The mechanical properties and the deformation mechanisms of three beta titanium alloys designed in order to present a values of Bo-Md and e/a as close as possible are investigated by tensile test, XRD profiles and MET observations. The contribution of electronic approach to predict beta phase stability is also discussed. The results obtained are as follows.

The three alloys display different mechanical behavior and different deformation mechanisms. For the TNZT alloy, the phase transformation from the $\beta$ phase to the $\alpha$ " phase is induced by stress during the deformation process in the $\beta$ phase. The TNZ alloy is characterized by typical elastoplastic behavior and the transformation from $\beta$ phase to $\alpha$ " phase is not observed for this alloy. And the binary TN alloy reveals the presence of martensite after solution treatment.

The electronic criteria is very useful in the choice of the compositions in order to avoid the "scanning" and constitute a precious help to design these alloys. Some discrepancies are found between the results revealed in the present study and theoretical information given by Bo-Md diagram, it lets suggest that this approach must be completed by a systematic study of the effect of elements addition on Ms, in particular for ternary and quaternary alloys.

Effects of aging treatment on mechanical properties are also investigated. Aging treatments are effective to increase the critical stress for slip deformation, which improve the stability of superelastic behavior. The isothermal holding for short time at $400^{\circ} \mathrm{C}$ increases the recovery strain and the tensile strength due to the formation of $\omega$ phase, while keeping and even decreasing the Young's modulus. Short time holding can be a promising way to optimize properties.

\section{References}

1. S.G. Steinemann, Metal implants and surface reactions, Injury, 27 (1996)

2. S. Miyazaki, H.Y. Kim, H. Hosoda, Materials Science and engineering, A 438-440, 18-24 (2006)

3. J.I. Kim, H.Y. Kim, T. Inamura, H. Hosoda, S. Miyazaki, Materials Science and Engineering A 403, 334-339 (2005)

4. N. Sakaguchi, M. Niinomi, T. Akahori, J. Takeda, H. Toda, Materials Science and Engineering C 25, 363-369 (2005)

5. N. Sakaguchi, M. Niinomi, T. Akahori, J. Takeda, H. Toda, Materials Science and engineering C25, 370-376 (2005)

6. L. Wang, W. Lu, J. Qin, F. Zhang, Di Zhang. Journal of alloys and compounds, 469, 512-518 (2009)

7. X. Tang, T. Ahmed, H.J. Rack, Journal of Materials Science 35, 1805-1811 (2000)

8. M. Niinomi, Materials Science and engineering A 243, 231-6 (1998)

9. M. Tane, S. Akita, T. Nakano, K. Hagihara, Y. Umakoshi, M. Niinomi, Acta Materialia, 56, (2008)

10. M. Abdel-Hady, K. Hinoshita, M. Morinaga, Script Materialia 55, 477-480 (2006).

11. H.Y. Kim, Y. Ikehera, H.Y. Kim, H. Hosoda, S. Miyazaki, Acta Materialia 54, 2419-2429 (2006).

12. T. Akahori, M. Niinomi, H. Fukui, M. Ogawa, H. Toda, , Materials science and Engineering C 25, 248-254 (2005)

13. H.Y. Kim, H.Y. Kim, T. Inamura, H. Hosoda, Miyazaki S. Materials Science and Engineering A 438, 839-43 (2006) 